Artigo: $\mathrm{O}$ ato comunicativo entre a biologia autorreguladora e os agregadores linguísticos informacionais

\title{
O ATO COMUNICATIVO ENTRE A BIOLOGIA AUTORREGULADORA E OS AGREGADORES LINGUÍSTICOS INFORMACIONAIS
}

\author{
THE COMMUNICATIVE ACT BETWEEN SELF-REGULATORY BIOLOGY AND INFORMAL \\ LANGUAGE AGGREGATORS
}

Renato Martins*

\section{RESUMO}

Embora nem sempre comunicação seja sinónimo de linguagem, os recentes desenvolvimentos tecnológicos de partilhar conhecimento obrigam a uma reflexão sobre o lugar da linguagem assim como do próprio Homem dentro desta. Neste trabalho iremos explorar alguns aspetos históricos que originaram o moderno modelo de informação. Para isso tentaremos contrapor as perspetivas iniciais do séc. XX que concebem o organismo como um todo e manifestante de vitalismo. Paralelamente será necessário contrapor o modelo cibernético que baseia o ato comunicativo na matemática e cálculo de probabilidades sob perspetiva funcional e com o objetivo de atingir a organização. Este modelo, ao não conceder às entidades emissoras intenção própria necessitará de justificar-se pelo modelo mecânico de causação para descrever o ato comunicativo como retroativo, finalista e eficiente. Em contrapartida, encontraremos a dificuldade de incluir as linguagens informais neste mesmo paradigma, precisando destacar qual dos dois modelos, teoria dos sistemas ou cibernética, consegue melhor abarca-los.

PALAVRAS-CHAVE: Teoria da Informação. Teoria dos Sistemas. Propriedade Semântica. Comunicação. Biologia.

\section{ABSTRACT}

Although not always communication has been synonymous of language, recent technological developments related to shared knowledge lead us to reflect about the place of language as Men in this context. In this work we tend to explain some historical aspects that originated modern information model. We will try oppose the initial perspectives of the $20^{\text {th }}$ century that conceived organism as a whole that expresses vitalism. At the same time it will be necessary to oppose the cybernetic model that ground communication in mathematics and probability

\footnotetext{
* Centro de Filosofia da Universidade de Lisboa, Portugal. E-mail: renatomartins@portugalmail.com.
} 
calculus inside a functional perspective with the goal of achieving organization. This model, that doesn't concede intention qualities to its issuing will have to be justified by classical mechanics causation model to describe communication act as feedback, goal-seeking and efficient. On the other hand, we will find difficulties to include informal ways of language in this paradigm, needing to highlight which of this two models, System Theory or Cybernetic, can better approach it.

KEYWORDS: Information Theory. System Theory. Semantic Property. Communication. Biology.

\section{INTRODUÇÃO}

A contemporânea cultura de transmissão linguística revela uma necessidade de conceptualização do formato desta interlocução a partir da compreensão de sua natureza assim como caracterização do espaço artificializado dos correntes media. Os processos de codificação subjacentes à transmissão da mensagem parecem destituir-se da vagueza intencional ou do sentido de pertença comum que estavam presentes. Os meios contemporâneos de comunicação destituídos deste contexto mútuo, caraterizados por espaços não partilhados e de transmissão formal resumida à partilha da mensagem truncada no trabalho de orientação na escolha da sinalização alfabética, levam a assumir uma produção linguística destituída de informalidade e nuances subjetivas que classicamente subsumiam o emissor e recetor num mundo comum de compreensão mútua instantânea. A perda desse pano de fundo comum causada pela emergente globalização e capacidade tecnológica de tornar o emissor ubíquo revela uma transmissão diferente, desde logo no tempo e no espaço, da escrita de autor publicado para a posteridade (pela obra que sobrevive secularmente) ou a escrita de autor destinada à receção em espaços distantes e alheios (como a correspondência ou o jornalismo). De fato, este novo autor não revela uma qualidade de acabamento que justifique um plano de descrição linear e compreensivo do tema abordado, pelo fato de a intenção de criação de uma narrativa encontrar o seu espaço condicionado por uma interlocução questionadora instantânea, que coloca em causa a propriedade ou fixidez do elemento inicial com vista à intenção comunicativa.

Para caracterizar a natureza deste espaço, novo porque é resposta decorrente dos condicionalismos tecnológicos, e, paradigmático, porque é resultado de fundamentos 
Artigo: $\mathrm{O}$ ato comunicativo entre a biologia autorreguladora e os agregadores linguísticos informacionais

teorizados nas áreas da biologia e teoria da informação durante os séculos XIX e XX, interessa explorar estas mesmas assunções. Verificar semelhanças entre a linguagem contemporânea decorrentes da nova postura informacional, e, os processos de interação da Natureza, denota isomorfismos a nível causal mas também nos mecanismos de apropriação do objeto externo.

\section{BIOLOGIA, FÍSICA E COMUNICAÇÃO}

É na incapacidade de comprovação do vitalismo nos seres animados que se propõe o avanço das teorias que rejeitam a liberdade no seu sentido clássico ao organismo e propõe uma abordagem inter-actuante das partes conjugadas entre si sob dependência das dinâmicas externas. Em níveis inferiores à consciência e comunicação humana, é o comportamento celular, as respostas neuronais e a fisiologia das ações motoras que servirão como evidência empírica para redefinir a abordagem comunicativa enquadrando-a como uma análise de elementos parciais capazes de justificar o todo.

Indagava-se o biólogo alemão Hans Driesch acerca da capacidade de regeneração dos organismos que parecia indicar um plano interno de desenvolvimento independente das afeções externas. O ramo que o biólogo procurava dar continuidade referia-se à capacidade criativa momentânea, algo que verificou a nível celular, insinuando deste modo uma vitalidade permissiva à sobrevivência e à realização do desígnio da espécie. A ênfase autoral e do emissor como plenitude mesmo em contato com contingências alheias, permitiria consagrar o ser na ação como momento de arte, pelo atributo de criador e nobre superior às tendências mecanicistas ambientais que a res extensa de Descartes havia legado. A enteléquia que Driesch preconizava, espírito vital que atribui aos organismos mais microscópicos desígnio para atingir estados finais conforme uma volição intrínseca servia de caminho para negar a eficácia dos fenómenos causais nos elementos animados. Mas além da causalidade reinante no paradigma científico um novo impacto se ia entronizando na mundividência dos fenómenos reversíveis caracterizadores da linearidade da cosmologia das leis absolutas: a entropia. A impossibilidade do movimento perpétuo, assim como a diversidade das formas de força existentes na Natureza levam à redefinição da locomoção como manifestação de propriedades escondidas como a gravidade, a elasticidade, o calor ou os campos elétricos. Muito embora a transmissão das forças fosse possível, segundo a primeira lei da termodinâmica preconizada por Helmholtz, como um princípio de conservação do 
movimento, o problema continuará a subsistir: como manter a força no próprio processo de transmissão? As leis imutáveis do Universo de Newton e os animais máquina de Descartes encontraram deste modo o problema da sua própria regulação, denotado empiricamente nas recriações artificiais e mecânicas destes modelos. Carnot (1825) explorava o risco destas transferências nas máquinas a vapor, receando o desequilíbrio pela impossibilidade de renovação energética. Após a máquina perfeita divina teorizada por Descartes ou Malebranche, a mecânica clássica enfrentava o problema da auto-sustentabilidade correndo o risco de regresso às conceções cosmogónicas do estado original. Driesch (1907) tentava também ultrapassar este problema com a sua própria perceção de um vitalismo que integrasse a termodinâmica salvando os seres vivos do risco de colapso, dotando-lhes a potência de equifinalidade, em que os mesmos poderiam resistir a acidentes ou controvérsias no percurso de desenvolvimento e objetivar-se em percursos estáveis. Mas esta solução para-física do biólogo alemão não encontrou ecos nos desenvolvimentos científicos que continuaram a ocorrer durante o restante século XX. Estava presente na fantasia dos físicos de então a figura do demónio de Maxwell, batizado com o nome do seu autor, e que servia de controlo do comportamento das transferências calóricas garantindo estabilidade. O simbolismo do demónio de Maxwell servia de inspiração a uma forma de pensar caracterizada pelo controlo experimental elaborado por um imaginário investigador que fosse externo às manifestações naturais. Serviria também para regressar ao primeiro princípio da termodinâmica, tentando restabelece-lo através da palavra-chave organização. Dominar sob os princípios da incerteza, mesmo a nível microscópico, desvela as unidades operadoras que em relação criam unidades superiores, entendendo-se uma entidade holística: o sistema. A perceção identitária pela singularidade do comportamento e organização desses sistemas parte de dois princípios:

a) As partes colaboram entre si para suster aquilo que já é entidade - "o todo é mais que a soma das partes" (BERTALANFFY, 6, 1950);

b) As partes formam um conexo inter-causal em que na falta de uma todo o sistema está comprometido.

\section{FUNÇÃO E INTENÇÃO COMUNICATIVA}

Esta última aceção compromete-se com o mecanicismo clássico, muito embora faça derivar as qualidades previsíveis das ações para a reordenação das componentes derivado da contingência dos fluxos afetantes externos. Tal arranjo fluído para a identidade do sistema- 
Artigo: $\mathrm{O}$ ato comunicativo entre a biologia autorreguladora e os agregadores linguísticos informacionais

mecanismo formaliza-se no feedback, na emissão retroativa que reformula o tipo de mensagem, tornando-a multiplamente diretiva em vez de apenas transmissora - o “multiplexing” (NEUMANN, 1956, p. 70). O comando e controlo entre partes ativas necessitará de ser abrangido pela interação complexa de vários canais que se ligam pela comunicação de informação. Neste sentido encontra-se subjacente na natureza da informação um meio de explicitação do princípio ordenador. Uma intencionalidade da difusão informativa, quer contendo na sua natureza uma finalidade ou a "consciência" de um princípio, encarna o princípio decisor no meio que é a mensagem. A codificação de qualquer movimento ou intenção obriga ao exercício exploratório da linguagem da mensagem, que conforme as dimensões adotadas pode ser binária ou alfabética. Para a comunicação neuronal, a linguagem binária constitui o encaixe interpretativo para aferir as ligações do sistema nervoso, ajudado por algumas características como: unidades (neurónios), comunicação (fenda sináptica) e as interligações que permitem disjunções e negações. Seguindo o programa de Hilbert, o sistema nervoso está aparentemente apto a conter uma linguagem puramente lógica proposicional (PITTS, 1943). Esse sistema coordenativo top-down (PENROSE, 1995) encontra no entanto dois condicionalismos para o fracasso:

i) Os paradoxos da linguagem que abrem caminho à finitude das cadeias fechadas sem resultados pertinentes lógicos ou semânticos;

ii) A dificuldade de adaptação às modificações tanto externas como do próprio sistema.

Deste último caso, voltamos a referir o carácter irreversível e não-determinista do universo entrópico, desestabilizador das condições propostas periodicamente. A probabilidade e a estatística mecânica ganham terreno de afirmação num modelo de conhecimento estocástico previsor de séries ou novidades. A $2^{\mathrm{a}}$ lei da termodinâmica transita de definição eletromagnética para fator influente na transmissão da mensagem informativa numa interpretação matemática da linguagem, desprovida de sentido subjacente. A redundância permite a estabilidade do sinal, que prolongado se estende na monotonia. É a entropia que apresenta condições para diversificação do canal transmissor e como assegurador de estímulos à adaptação do sistema. Neste sentido a riqueza linguística assume-se pela heterogeneidade dos emitentes externos assim como a recetividade multifacetada que a comunicação pode assumir. Esta riqueza não se deve contudo confundir com capacidades linguísticas de sinalização fidedigna de realidades diversas ou de descrições de estados abstratos de 
complexidade controversa. A nível linguísticos, e, concebendo o emissor e recetor como entidades matemáticas (SHANNON, 1948) não se precede a mensagem de experiência ou intuições, mas de um conjunto vasto de possibilidades de confrontação com o ente pensante. Retemos as palavras de Merleau-Ponty:

\footnotetext{
Hoje, como outrora, só há contudo uma única maravilha considerável, é verdade -, que é o homem falar ou calcular, em outras palavras, que ele tenha constituído para si esses prodigiosos órgãos, o algoritmo, a linguagem, que não se desgastam, mas ao contrario crescem com o uso, capazes de um trabalho indefinido, capazes de produzir mais do que lhes foi colocado, e no entanto não cessam de se reportar às coisas. (MERLEAU-PONTY, 1991, p. 215).
}

Do orador informacional, fortemente comprometido com o Pathos, assume-se uma dinâmica transmissiva com preocupações balizadoras quanto ao conteúdo e propósito da mensagem. $\mathrm{O}$ alfabeto coordenado para dar lugar a palavras, perde desde logo a riqueza fonética que o sujeito associa ao significado. Sendo que esta semântica é um produto de ligações com vivências próprias que ao próprio diz respeito e onde encontra o sentido nas suas próprias palavras. No paradigma informacional, o sentido é remetido para o propósito da comunicação, sendo a eficiência das trocas semióticas o padrão de congruência e avaliador do funcionamento do jogo linguístico. Consequentemente, a formação do dado cultural em oposição à aculturação, traduz-se na ênfase dada à normatividade enquanto barreira definidora da operação de culturalização. Enquanto ausente a fala sub-construída do pensar introspetivo e dos hábitos informais de vivências, o sujeito orador vincula-se ao processo atenuador destes mesmos elementos, denotando-se pela aderência à mensagem pelo posicionamento de estímulo. Na própria tradição cibernética, o estudo do pensar configura-se na caixa preta, ou seja, remete-se para operacionalidade dos inputs e outputs. Muito embora inclusiva da linguagem dentro da tipologia de estímulos, a caixa preta é um conceito que subsume a psicologia ao comportamento, não permitindo antever os acontecimentos mentais decorrentes dos processos de transmissão. Daí que esta mesma linguagem se defina enquanto potência relativamente aos resultados ocorridos advindos do output que a caixa pode fornecer. A essência não partilhável, distante da observação empírica, apenas se manifesta. Além da redutibilidade aos conteúdos manifestos, é assente também pela teoria referida que os resultados obtidos são antecedidos pelo apelo, função de input e estimulante do cérebro. $\mathrm{O}$ locus determinador ocorre nas interações que se irão querer cada vez mais instáveis, considerando a variabilidade da comunicação a virtude que destitui a persona da sua fixidez, 
Artigo: $\mathrm{O}$ ato comunicativo entre a biologia autorreguladora e os agregadores linguísticos informacionais

encarrilando-a na fluência das coisas. Assumidos como virtuais pois provisórios, a elementaridade transforma-se em transitoriedade, qualidade exigida pelo trânsito das trocas cognitivas. Tal visão não demite aparentemente o estado de vacuidade que o pensar parece devotado. A não observação dos sentires e ignorância dos estados intuitivos continua a exigir uma resposta por parte do emitente orador dentro do projeto comunicativo, daí a aprendizagem manter um papel catalisador na súmula das operações. O feedback negativo surte como condição adaptativa da mente que se assume como responsiva perante as hipóteses seriais que os apelos de integração impõe. A função coordenativa substitui então os desvios arbitrários que apenas serviriam para tergiversar a ação ocorrente em invariância, que motivaria a instabilidade do sistema e concomitante degeneração. As respostas não são neste meio contudo nem determinadas ou causadas, mas decorrentes de um conjunto de opções cardinais onde estão consideradas diversos tipos de variáveis. A mente calculante atribui a si o fator de decisão perante a informação delegada, fazendo corresponder este dado ao recetor devido, mas transformando-o em matéria depurada pela operação coordenativa efetuada. Em Ross Ashby, tal atitude corresponde à calibragem entre recebido e percecionado, e, persistência na persecução do objetivo a alcançar (goal-seeking) (ASHBY, 1960, p. 219), e, em Claude Shannon (1948, p. 22) à eliminação de ruído no canal de transmissão com vista à evidenciação da mensagem limpa de equívocos. O fluxo transmissivo pode então conter elementos de níveis diferentes, quer seja a temperatura, a manifestação corporal, mas também num ponto mais elevado da hierarquia a insinuação, o lapso, a ironia, a metáfora ou os jogos verbais. Como atingir a mensagem de comando dentro da esfera verbal, é um dos objetivos do paradigma da comunicação por informação. A aglutinação das emissões atrás referidas e consideradas como desvios da mensagem de comando necessita de uma resposta teórica que admita na sintaxe qualidades que assegurem a correção na transmissão. Os elementos informais que invadem a linguagem e à qual essa não está possibilitada de enformar mantêmse como revelias no locus interativo tendente à organização e equilíbrio. Nos sistemas artificiais, como a computação, o problema não se coloca devido à natureza do próprio sistema, desenhado para funcionar com códigos de programação criados numa linguagem própria e eficaz, desde que endógena. Nesta unidimensionalidade, é o Homem que aprende novas formas simbólicas para uso no sistema artificial. Diríamos que aquele se desprende de si e de sua subjetividade para assumir uma linguagem auto-funcional pela razão de que os seus estímulos obtêm respostas que irão propor novos estímulos. Contudo os sinais comunicativos não-verbais, ou, verbais com insinuação, constituem armadilhas para o 
funcionamento correto das diretrizes sintáticas programadas, e no entanto o seu valor nas construções sociais é inquestionável. Trata-se do terceiro tipo de linguagem referido por Habermas, posterior às teorias formais ou de jogos linguísticos, e que entra num plano mais invisível: o pano de fundo da informalidade (HABERMAS, 1998).

\section{O PARTICULAR COMUNICADO}

Os códigos de convenção históricos que o sujeito herda e que permitem as construções sociais quotidianas, impregnam a mundividência não-aprendida que serve de conduta nas relações e atitudes do agente, assim como constituem formas de instantaneidade do sujeito reagente. Envolvido ao longo do crescimento em interações adaptadas às capacidades cognitivas, este dispõe de uma série de elementos sem codificação ou de identificação para a interação social, não concebendo conscientemente o regime das polaridades axiológicas referentes à mensagem em uso. Esta envolvência denota um regime de empatia, enternecimento e valorização pelos termos emitidos e recebidos, como que o sujeito fosse capaz de encontrar, embora sem entender, a singularidade destes mesmos termos. A teoria da linguagem solidifica a tese de que a universalidade da palavra garante o cunho objetivo necessário para a produção da interação ao mínimo exigível. É neste sentido que Locke nega a possibilidade de existirem palavras para descrever particulares, apontando três razões:

i) É impossível dar nomes a todos os particulares - tese referente a limites linguísticos;

ii) Se tal fosse possível, seria desnecessário - tese referente à funcionalidade linguística;

iii) Nomes particulares não aumentariam o conhecimento humano - tese da desnecessidade da linguagem individual.

Para o filósofo inglês a linguagem surge como separação das coisas e forçosamente exercício de abstração:

\footnotetext{
Words become general by being made the signs of general ideas; and ideas become general by separating from them the circumstances of time and place and any other ideas that may tie them down to this or that particular existence. By means of such abstraction they are fitted to represent more than one individual. Every individual that conforms to that abstract idea is of that sort (as we call it). (LOCKE, III, I, p. 6).
}

Verte daqui a fundamentação das palavras como conjuntos aglutinadores de partes que se encontram pela semelhança, e que ausentes de referencial de origem real, encontrariam o seu sentido dentro de uma hierarquia categorial concedente a cada uma estatuto próprio no 
Artigo: $\mathrm{O}$ ato comunicativo entre a biologia autorreguladora e os agregadores linguísticos informacionais

resultado da expressão. De fora desta organização mecânica da sintaxe estariam fatores como a tradição histórica, a intencionalidade facial-motora ou a intuição criativa, sendo que o primeiro sugeriria uma linguagem inevitável; o segundo uma apropriação da linguagem nãoverbal aos códigos transmitidos; e à terceira um jamming obstrutivo da organização em curso. Contudo, cada uma destas, à sua maneira, apresentam elementos implícitos da comunicação de estados particulares manifestados nas palavras de afeto (evidenciadoras de pertença), onomatopeias (evidenciadoras de expressividade corporal) e neologismos (evidenciadores do sentido criador). Cumpre saber se fatores como estes terão o seu lugar na construção da complexidade advinda do paradigma organizativo, assegurando para isso se estes não constituirão modos de força entrópica que instigam o sistema à adaptação. Como resposta mais conciliadora encontramos a definição de isomorfismo nas diferentes escalas e qualidades de conhecimento tal como nos é legada por von Bertalanffy, para conceber um modo de confluência que assuma as diferentes formas de comunicação anteriormente propostas. Acima de explicar o fenómeno das qualidades primas das manifestações comunicativas, o isomorfismo acredita em leis semelhantes que se manifestam em diferentes escalas, daí o convite à unificação das diferentes tipologias de conhecimento. A interação comunicativa assume deste modo relevância, a nível biológico, geo-histórico, social e pessoal, destacando cada um destes estudos em homologias que permitem definir leis que se encontram, independentes do causacionismo. Aportamos ao seguinte exemplo:

when we investigate the development of the Germanic languages, it may he observed that, beginning with a primitive language, certain sound mutations occurred in parallel development in various tribes, though these were geographically located far apart from each other; in Iceland, on the British Isles, on the Iberian peninsula. Mutual influence is out of question; the languages rather developed independently after separation of the tribes, and yet show definite parallelism. The biologist may find a corresponding principle in certain evolutionary developments. (BERTALANFFY, 1950, p. 81).

A noção de isomorfismo, com a possibilidade de evolução paralela retira o monopólio à conceção da linguagem enquanto mera sintaxe, pois ao permitir fenómenos semelhantes em realidade geográficas distintas, admite-se o desligamento comunicativo entre as línguas. A proposta de Bertalanffy vai deste modo permitir a abertura para algo mais além da comunicação de feedback preconizado pela cibernética, relegada para "regulações secundárias" (BERTALANFFY, 1950, p. 150). Mantendo em certo sentido o sentido evolutivo orgânico de Driesch, cumpre-se uma auto-regulação que não necessita do estímulo 
informacional. $\mathrm{O}$ ato comunicativo é mais abrangente na obrigação de conciliar algo mais que o comando e controlo, tal como as manifestações extra-verbais em perfeita coordenação com a mensagem final transmitida. Ao considerar afetividades linguísticas e coordenações motoras bifurca-se na natureza entre o plano objetivo, como propugnava Locke, e o subjetivo. Mas o modelo de feedback veio a ser requalificado pela emergência das novas tecnologias, como a internet, que permitem a comunicação pela tele-presença. Não se tratando aqui de um modelo de programação e organização, a ausência de corpo destitui os comunicantes do pano de fundo, atrás referido por Habermas, reguladores fluentes nas interações que eliminam o Gemeinwelt - mundo comum das vivências partilhadas, onde ocorre a husserliana kundgebende funktion - função de manifestação não-expressiva ou linguística, cujos signos indicam a vivência daqueles que a falam (ALVES apud HUSSERL, 2009, p. 41). Denotando a origem da problemática relacionada com a $2^{\mathrm{a}}$ lei termodinâmica e verificando a transição que esta efetuou da ciência eletromagnética à teoria da informação, agrava-se a revisão dos efeitos entrópicos por fatores não naturais e exclusivamente informacionais. Dentro desta perspetiva seria o caos simbólico a desafiar a constância organizada das linhas de comando e o excesso de comunicação, o jamming e a insinuação verbal constituiriam variedades no jogo linguístico discorrentes ao sistema, equivocantes e alimentadores da incongruência. Neste sentido, a teoria dos sistemas não alcança o seu total princípio de hemóstase pela coordenação das várias qualidades obtidas pela Natureza e pela Biologia, e um princípio matemático da comunicação como Shannon propõe faz depender troca linguística da análise discreta dos símbolos - favorecido pelas linguagens tradicionais assentes no alfabeto, e pelas redundâncias reafirmantes da normalização linguística. Na caraterização deste tipo de pensamento técnico, Lucien Sfez (1994, p. 129-131) evidencia 5 postulados:

\footnotetext{
i) A questão é reduzida ao problem solving;

ii) O humano opera como um sistema de informação;

iii) Um sistema de informação é um sistema de signos;

iv) Este sistema de signos assenta sobre uma concepção exclusivamente representativa;

v) A representação é espacial. O que se deve observar é a exterioridade da representação da tarefa, exemplo das memórias que devem ser exteriores.
}

O tipo de teleologia releva aqui um modo diferente: o comunicante pressupõe um objetivo a alcançar que altere o estado do atingido. A receção corresponde a uma estimulação que afete o funcionamento próprio, considerada a diversidade instigadora para a mudança. Ao invés, os sistemas biológicos posicionam-se para estados estacionários, e sua abertura consiste 
Artigo: $\mathrm{O}$ ato comunicativo entre a biologia autorreguladora e os agregadores linguísticos informacionais

na estabilização destes mesmos. Mas não há um canal pré-definido e com formato rígido para esse objetivo, pois são consideradas manifestações físicas e culturais mais amplas que mantém o sistema no seu estado aberto. A teoria dos sistemas não procura encontrar a forma de enclausurar o sistema, mas pelo contrário, é pela irreversibilidade termodinâmica que vislumbra a força "criativa" às entidades biológicas.

\section{CONCLUSÃO}

O modelo comunicativo vigente através das modernas tecnologias de informação perspetiva o Homem na sua manifestação linguista como operário da fala, indicador dos dados de ação acabando ele mesmo como produto resultado dos dados recebidos. Adicionalmente, a univocidade exigida exclui o dizer enquanto mostrar (Sagan) da visão do mundo, caindo num agressão à língua, por esbater num limite que não encontra o “informulado" (HEIDEGGER, 1995, p. 33-39). Ao invés, encontramos na aproximação sistémica um modelo de complexidade capaz de abranger subtilezas marginais da comunicação que desvirtuam o Homem do objetivo de problem solving exigido no modelo informacional. As estruturas pré-linguisticas encontram uma justificação de existência e desempenho coerente concebendo-se a interação humana num vasto campo de fatores menos visíveis, e que a teoria sistémica procura inclui-los pela visão de modos de ação transversais isomórficos à expressão da vontade. $\mathrm{O}$ modelo não cai contudo no vitalismo proposto por Driesch a que aludimos atrás, mas também não absolutiza leis de tipo universal como Newton. Ambas as perspetivas, volição anímica radical e absolutismo cosmológico encontram tanto a decadência da metafísica como a irreversibilidade dos fenómenos como contraditórios fortes. Aquilo que poderíamos intitular de propriedade semântica terá que admitir uma linguagem código que consegue ir além dos elementos lexicais da expressão. Muito embora a presença sinalizadora da mensagem familiar aos interlocutores, é o referencial às diferentes dimensões ontológicas que se verifica, quer seja a tradição, a familiaridade, o afeto, a disfunção cognitiva na aprendizagem dos mesmos, ou a fantasia associada ao termo. $\mathrm{O}$ sentimento próprio, a propriedade sob os efeitos íntimos decorrentes da comunicação, poderá não ser objeto de estudo, mas a aproximação mais denunciadora é alcançada por uma teoria que englobe diferentes dimensões: biológica, histórica, geográfica e linguística assim como preconizado pela teoria dos sistemas. A descorporalização do conhecimento permitida através da comunicação instantânea à distância encerra o sujeito comunicante, tanto emissor como 
recetor, numa unidimensionalidade que limita o ato ao estudo sintático hierarquizado pelas associações categoriais. Nesta orientação seguia, na história da tecnologia, o Memex, em que os aspetos criativos estariam dedicados apenas à seleção de dados (BUSH, 1945), e que na recente internet se verifica nas hiperligações, agregação de temas e listagem alfabética. Notemos que este mesmo sentido agregador do digitalismo é um caminho para a massificação das mensagens e sintetização em conjuntos da comunicação. Perde-se deste modo a analogia, função espelho entre a linguagem e realidade, em que o encontro entre sintaxe e respetiva referência colocaria o Homem na barreira intransponível da evidência da sensação. A explosão informativa que verificamos nos dias de hoje, ao invés, desvaloriza tal obstáculo e concede ao limite do pensar humano um percurso mais abrangente de informação. Até ao ponto em que esta mesma informação seja demasiado grande para a singularidade de um pensamento só, necessitando de um acompanhamento do artificial, das tecnologias de comunicação, mais rápidas e capazes de processamentos macroscópicos.

\section{REFERÊNCIAS}

ALVES, Pedro M. S. Intersubjectividade e comunicação. Lisboa: Centro de Filosofia da Universidade de Lisboa, 2009.

ASHBY, William Ross. Design for a Brain. New York, John Wiley \& Sons. Inc, 1960.

ASHBY, William Ross. Principles of the self-organizing system. In: Principles of SelfOrganization: Transactions of the University of Illinois Symposium, H. Von Foester and G.W. Zopf, Jr (eds). London, UK: Pergamon Press, 1962.

ASHBY, William Ross. Introdução à cibernética. Tradução Gita K. Ghinzberg, Ed. Perspectiva: São Paulo, 1970.

BERTALANFFY, Ludwig von. General System Theory Foundations, Developments, Applications, New York: George Braziller, 1968.

BERTALANFFY, Ludwig von. An outline of General System Theory. 1950.

BUSH, Vannevar. As we may think. The Atlantic Monthly, Vol 176 N 1, p. 101-108, 1945.

CARNOT, Sadi. Reflections on the motive power of fire and on machines fitted to develop that power, 1825 .

DRIESCH, Hans. Science and philosophy of the organismo. Adam and Charles Black London, 1908. 
Artigo: $\mathrm{O}$ ato comunicativo entre a biologia autorreguladora e os agregadores linguísticos informacionais

HABERMAS, Jürgen. On the pragmatics of communication. Maeve Cooke (org.). Cambridge, MIT, 1998.

HEIDEGGER, Martin. Língua de tradição e língua técnica. tradução Mário Botas, Ed. Veja, 1995.

HELMOHOLTZ, Hermann von. On the conservation of force. The Harvard Classics. 190914.

MCCULOCH, Warren S.; PITTS, Walter. A logical calculus of the ideas immanent in nervous activity. Bulletin of Mathematical Biophysics, Volume 5, 1943.

MERLEAU-PONTY, Maurice. Signos. tradução Maria Ermantina Galvão Gomes Pereira. São Paulo: Martins Fontes, 1991.

NEUMANN, John Von. O computador e o cérebro. tradução Manuel Marques. Ed. Relógio d'água, 2005.

NEUMANN, John Von. Probabilistic logic and the synthesis of reliable organisms from unreliable componentes. Princeton University Press, 1956.

PENROSE, Roger. Shadows of the mind. Vintage, 1995.

SFEZ, Lucien. Crítica da comunicação. tradução Serafim Ferreira. Ed. Piaget, 1994.

SHANNON, Claude. E. The Mathematical Theory of Communication. The Bell System Technical Journal, Vol. 27, pp. 379-423, 623-656. July, October, 1948.

WIENER, Norbert. Cybernetics: or control and communication in the animal and the machine. The MIT Press, 1965.

WIENER, Norbert. Human use of human beings. The Perseus Book Group, 1988. 